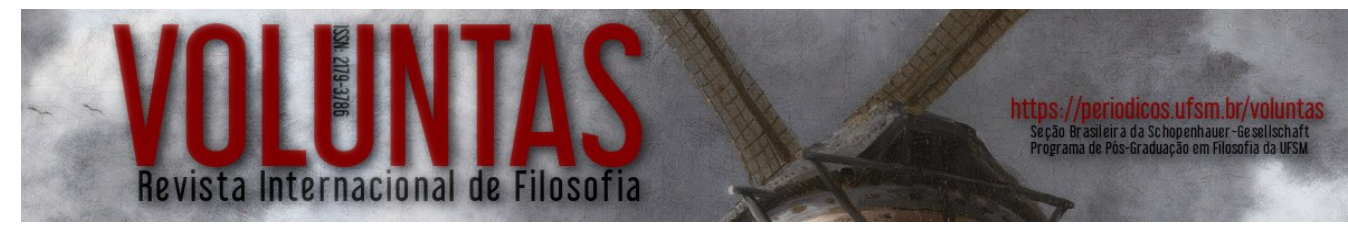

ISSN: 2179-3786

DOI: $10.5902 / 2179378633639$

\title{
Clément Rosset e a duplicação do real. $O$ paradoxo do ator entre a proteção fracassada e a aceitação jubilosa
}

\author{
Clement Rosset and the duplication of the real. The paradox of the actor between the failed \\ protection and the joyous acceptance
}

\author{
Gustavo Bezerra do Nascimento Costa \\ Doutor em Filosofia pela UERJ \\ Professor adjunto da Universidade Estadual do Ceará (UECE) \\ E-mail: gustavobn.costa@,uece.br
}

Resumo: Em O real e seu duplo, Clément Rosset aponta para a estrutura paradoxal de duplicação do acontecimento, do mundo e do homem operada pela ilusão que anseia por ser, ao mesmo tempo, ela e outra. Duas alternativas éticas se descortinariam a partir daí: proteger-se do real pela criação paradoxal e fracassada de um duplo, ou aceitá-lo por meio do júbilo heroico. Tal estrutura, com efeito, remete ao paradoxo que, já em Diderot, caracterizaria o ator em cena: "vir a ser todos sem ser ninguém". E é tendo como imagem esse mesmo ator - dessa vez, nos processos de cultivo e incorporação que, segundo Stanislavski, comporiam o personagem - que se pretende apresentar uma terceira possibilidade, presente já nos gregos, cujo princípio demanda dominar o kairós, o tempo oportuno à ação, para com ele roubar do acaso a astúcia que o converte em destino.

Palavras-chave: Hipocrisia; Engano; Autoengano; Mêtis; Kairós.

Abstract: In The real and its double, Clément Rosset points out to the paradoxical structure of duplication of the world, the man and the events operated by the illusion that yearns to be, at the same time, itself and another. Two ethic alternatives would come out: to protect yourself from the real by the paradoxical and failed creation of a double, or accept it through the heroic jubilation. This structure, in fact, refers to the paradox that, since Diderot, would characterize the actor in scene: "to become everyone, being no one". Taking the image of that same actor - this time, focusing the processes of cultivation and incorporation that, according to Stanislasvki, would make up the character - we intend to present a third possibility, known by the Greeks, whose principle demands to dominate kairós, the opportune time to the action, and then, stealing from the chances the cunning that turns them into fate.

Keywords: Hypocrisy; Deceit; Self-deception; Mêtis; Kairós.

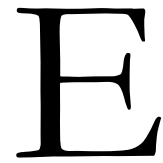

m O real e seu duplo, Rosset toma a ilusão como mote para pensar a estrutura ontológica de duplicação do acontecimento, do mundo e do homem como forma esquiva e evasão ante a lida com o real - busca paradoxal e reiteradamente fracassada por um outro, em nome do qual se recusa e 
sacrifica o único1. Paradoxal, por um lado, porque requer ser ao mesmo tempo ela própria e outra: "Não há eu que seja apenas eu, não há aqui que seja somente aqui, não há agora que seja apenas agora" 2 . Mas, por outro lado, também é fracassada porque se reconhece no duplo, tarde demais, o próprio real do qual se pensava estar protegido: "Esta é a maldição da esquiva: reenviar, pelo subterfúgio de uma duplicação fantasmática, ao indesejável ponto de partida, o real". "O real tem sempre razão", por isso a fuga é sempre um erro. Como afirma ainda: "Toda auto-satisfação ilusória - deveríamos dizer: toda auto-satisfação? - pertence no fundo a este mesmo esquema duplicatório"3. O paradoxo e seu consequente fracasso estariam, então, na própria tentativa de reconhecimento ou "captura de si mesmo" por meio de um outro, na medida em que se busca "justamente o que é impossível de apreender". Como não se escapa ao destino da "coincidência de si consigo", essa captura de si mesmo implicaria, paradoxalmente, a própria renúncia a esta captura - daí o desespero, aqui retrodatado, de Heinrich von Kleist ante a impossibilidade, imposta pela atividade consciente, de uma espontaneidade compreendida como "coincidência absoluta com o real"4. Com a própria condição humana, portanto, perde-se irremediavelmente a pureza do gesto espontâneo. Mas por outro lado, afastar-se de si mesmo, isto é, recusar ser ou mesmo aparentar ser "aquilo que se é" implicaria, não obstante, tornar a ser, ou aparentar ser precisamente isto ou aquilo que evitamos $\operatorname{ser}^{5}$.

Tratando deste tema a partir da moral das fábulas de Esopo, Rosset aponta então para duas alternativas éticas: proteger-se do real pela criação paradoxal e fracassada de um duplo ou aceitá-lo por meio do júbilo, sempre tendo em mente o verso de Sêneca: "O destino guia aquele que consente e arrasta aquele que recusa". Daí a necessidade de "aceitar corajosamente a sorte que nos espera e não trapacear com ela", sob pena de cair no estratagema do destino, de nos fazer agentes de nossa própria desgraça ${ }^{6}$. Diante dessa estrutura paradoxal de duplicação do acontecimento, do mundo e do homem operada pela ilusão - seja ela: oracular, metafísica ou psicológica - que anseia por ser, ao mesmo tempo, ela e outra, dois caminhos se descortinariam: proteger-se do real pela criação paradoxal e fracassada de um duplo, ou aceitá-lo por meio do júbilo heroico. A lida com o real apresentaria, então, esses duas alternativas possíveis: "o simples, que consiste em aceitar a coisa, e até regozijar-

\footnotetext{
${ }^{1}$ ROSSET, C. O real e seu duplo, p. 71-2.

${ }^{2}$ Idem, p. 85-6.

${ }^{3}$ Idem, p. 110-2.

${ }^{4}$ KLEIST, H. Teatro de marionetes, p. 97 e 100-101. Para Bornheim, o que diferencia e separa Kleist dos demais românticos é justamente o desespero quanto à possibilidade de felicidade advinda com a suposta espontaneidade do instante: o Zeitgefühl. "O inesperado instante de rara e nova felicidade é um logro", na medida em que estamos irremediavelmente condenados à atividade consciente (Cf. BORNHEIM, G. O sentido e a máscara, p. 100-1). Cf. também: ROSSET, C. O real e seu duplo, pp. 15-16, 31-33 e 45-46.

${ }^{5}$ KLEIST, H. Teatro de marionetes, p. 97 e 85-87, respectivamente.

${ }^{6}$ ROSSET, C. O real e seu duplo, p. 21-22 e 85-86.
} 
se com isso; e o complicado, que consiste em recusá-la" - portanto, ou a aceitação jubilosa, ou a evasão autoenganada ${ }^{7}$.

Embora concordando com Rosset quanto a esses dois itinerários - desde já saliento que não se trata de criticá-los em seu pressuposto ontológico -, defendo que seria possível apresentar ainda uma terceiro. Também presente nos gregos e não menos trágico, essa alternativa implica roubar do acaso a astúcia que move o engano e dominar o xa€ós [kairós], o tempo oportuno à ação. Trilhá-la requer uma atenção à mêtis - a forma de inteligência conjuntural, astuciosa e prudencial cujo princípio reza que "só o mesmo age sobre o mesmo"8 e que desde o século IV da outra era tem permanecido à margem do discurso filosófico, mas que, reiteradamente, tece os liames para a lida com os acasos:

Precedendo o kairós tão rápido ele seja, é a mêtis que desempenha contra ele o efeito da surpresa; ela pode "apreender" a ocasião à medida que, não sendo "leve", ela souber prever a continuação dos acontecimentos e preparar-se de mais longe?.

Seguindo as análises de M. Détienne e J-P. Vernant em Mêtis: as astúcias da inteligência, para os gregos, a mêtis:

[é] uma forma de pensamento, um modo de conbecer; ela implica um conjunto complexo, mas coerente, de atitudes mentais, de comportamentos intelectuais que combinam ofaro, a sagacidade, a previsão, a sutileza de espirito, o fingimento, o desembaraço, a atenção vigilante, o senso de oportunidade, habilidades diversas de uma experiência longamente adquirida; ela se aplica a realidades fugazes, móveis, desconcertantes e ambiguas, que não se prestam nem à medida precisa, nem ao cálculo exato, nem ao raciocínio rigoroso ${ }^{10}$.

Como defendo, nesse caminho estaria então implicada a capacidade de, pela mêtis, na atenção ao kairós, o tempo oportuno, roubar dos acasos a astúcia que move o engano.

É importante retomar aqui a leitura feita por Détienne e Vernant do tratado d'A inteligência dos animais, de Plutarco, e de um modo geral, do bestiário grego associado à mêtis, à inteligência astuciosa. Para aqueles autores, seria necessário distinguir nos gregos entre dois tipos de homem: $\pi 0 \lambda \dot{u} \tau \varrho o \pi \omega \varsigma$ [polýtropôs], o homem

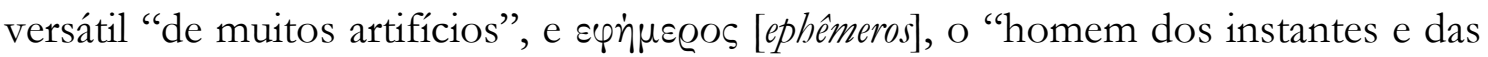
mudanças". Ambos se caracterizariam pela mobilidade, pelo movimento e por alguma relação com o engano. Porém, difeririam radicalmente em um ponto essencial: um é

\footnotetext{
7 Idem, p. 68-69. Um interessante paralelo poderia ser aqui feito entre o processo descrito por Rosset, de "duplicação do acontecimento" próprio à enunciação oracular (idem, pp. 20ss. e 49) e a ambiguidade intrínseca à Alêtheia do período arcaico, conforme descrita por Marcel Détienne em Os mestres da verdade na Grécia Arcaica - ambiguidade essa, desfeita com a dessacralização da palavra poética operada por Simônides e pela qual se dá a partilha das esferas da dóxa e da epistémê, respectivamente, entre a retórica e a filosofia. Não pretendo aqui levar adiante essa aproximação. Antes, diante das alternativas éticas colocadas por Rosset propor uma terceira. ${ }^{8}$ DETIENNE, M.; VERNANT, J-P. Métis: as astúcias da inteligência, p. 27.

${ }^{9}$ Idem, p. 22.

${ }^{10}$ Idem, p.11. Os romanos atribuíam estas características à sollertia (cf. Idem, p. 161).
} 
passivo ante a inconstância e o outro é ativo, ou seja, mestre, e não joguete. Enquanto o polýtropôs afirma-se por seu domínio: "flexível, ondulante, ele é sempre senhor de si, é instável apenas na aparência", ephêmeros é o homem inconstante "que se sente mudar a cada instante, experimenta seu ser de fluxo, gira ao menor sopro". De um ao outro há a exata distância que separa, em Plutarco, a habilidade polimórfica do polvo em relação à policromia do camaleão: "se a metamorfose deste último é produzida pelo medo, a do polvo se deve à astúcia"11. Essa distinção parece importante particularmente porque indica que para o grego, condenável não é o engano em si, mas ser enganado. E ainda mais, deixar-se enganar pelo próprio ardil e ser vítima da ironia do destino: não tomar as rédeas do engano e, como nos versos de Píndaro,

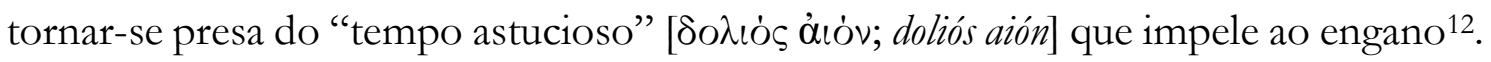

Não é fortuito que o polvo, assim como a raposa, tenha no pensamento grego o valor de modelo ético. Ambos seriam como a encarnação da astúcia no mundo animal: a da raposa culmina na "conduta da revirada", na reviravolta, como quando se faz voltar contra o adversário o argumento de que ele mesmo se serviu. Já o polvo simboliza, "na infinita leveza de seus tentáculos, a inapreensibilidade pelo polimorfismo". Cada um representaria um aspecto essencial - "duas faces indissociáveis" - da inteligência astuciosa que se configura como uma "arte dos liames". No polvo, particularmente - em que se molda uma mêtis cuja flexibilidade não parece dobrar-se às circunstâncias senão para dominá-las mais seguramente ${ }^{13}$ definir-se-ia um tipo de comportamento humano: o da politropia, oposto à atropia ou

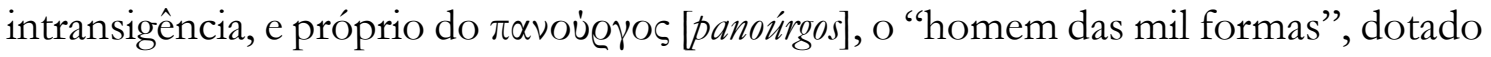
do inquietante prestígio de uma inteligência flexível (p. 277) ${ }^{14}$. Seu exemplo na tradição grega é Ulisses, o $\pi 0 \lambda \dot{u} \mu \tilde{\eta} \tau \iota \varsigma$ [polýmêtis], mas se poderia muito bem associá-lo a um referencial antropologicamente mais próximo: o Zé Pelintra - entidade do Catimbó e da Umbanda - e de um modo geral, o malandro. Afinal, se a "mêtis procede obliquamente", por sua vez, "o malandro anda assim de viés [...]”15.

\section{Paradoxo sobre o comediante: primeiro ato}

Decerto, como afirma Rosset, todo reconhecimento de si já estaria, de saída, fadado paradoxo. E com efeito, outro não seria o paradoxo que, para Diderot, caracterizaria o ator em cena. No diálogo Paradoxo sobre o comediante (1769), ele nos apresenta uma teoria

\footnotetext{
${ }^{11}$ Idem, p. 38ss. e 46-47.

${ }^{12}$ Idem, p. 46-47.

${ }^{13}$ Idem, p. 46-7.

${ }^{14}$ Idem, p. 277.

${ }^{15}$ Idem, p. 278. Na sequência, trecho da canção: $A$ Volta do malandro, composta por Chico Buarque para o filme A Ópera do Malandro, de 1985, dirigido por Ruy Guerra, com base no musical homônimo de 1978, com composições de Chico Buarque e dirigido por Luiz Antonio Martinez. O musical, como é sabido, inspira-se na "Ópera dos Mendigos" (1728) de John Gray, e na "Ópera dos três vinténs" (1928) de Bertolt Brecht e Kurt Weill (fonte: Dicionário Cravo Albin da Música Popular Brasileira, disponível em: http://www.dicionariompb.com.br).
} 
do ator cujas implicações filosóficas ultrapassam a de um mero tratado sobre a atuação. Nas vestes de um personagem, o filósofo define o ator como aquele que possui "igual aptidão para toda espécie de caracteres e papéis" e, sempre reconhecendo a si sob a máscara, consegue ser outro sem deixar de ser ele mesmo. Sua arte é a arte de tudo imitar. Mas de que maneira seria possível ao ator representar tão bem e passar de uma imitação a outra mantendo a ilusão desejada pelo público, sem que lhe seja necessário submeter-se à crença em seu personagem? É precisamente aí que se põe o paradoxo do ator com relação à sua arte, que é no fundo o paradoxo do autoengano: 16 "Se ele é ele quando representa, como deixará de ser ele? Se ele quer cessar de ser ele, como perceberá o ponto justo em que deve colocar-se e deter-se?"17.

O ator seria aqui o exato contraponto de Crátilo, no diálogo homônimo de Platão, que teria como propriedade fundamental "ser ele mesmo e não um outro"18. Para exercer bem a sua arte, dirá Diderot, é preciso que coexista nele "um espectador frio e tranquilo" daquilo que se passa "no mundo físico e no mundo moral". Exigese dele "penetração e nenhuma sensibilidade", já que a sensibilidade "nunca se apresenta sem fraqueza de organização". Segue-se daqui uma das mais belas frases do diálogo de Diderot, que condensa o que para ele estaria no cerne da arte do ator: "As lágrimas do comediante lhe descem de seu cérebro; as do homem sensível lhe sobem do coração"19.

Com efeito, a compreensão fundamental ao personagem do diálogo de Diderot é a de que: "ser sensível é uma coisa, e sentir é outra"20. Uma coisa, portanto, é a crença no objeto com o qual se lida; outra é a crença nas suas próprias virtudes para lidar com esse objeto. Como bem aponta Ana Portich em $A$ arte do ator entre os séculos XVI e XVII, a primeira é uma disposição passiva, ao passo que a segunda é ativa ${ }^{21}$ como expus acima, tal qual a distância que separa, entre os gregos, o ephêmeros do polýtropos. Por crer nas suas próprias virtudes, o ator escapa da crença no objeto, do apego sensível ao personagem, obtendo o distanciamento necessário em relação a sua obra: nesse caso, do sujeito-ator em relação ao objeto-personagem. É por essa distância artística e estética, enfim, que ele busca a verdade de seu objeto, ou seja, a expressividade de seu personagem; não nas coisas "como elas são na natureza", mas "na conformidade das ações, dos discursos, da figura, da voz, do movimento, do gesto, com um modelo ideal imaginado pelo poeta, e muitas vezes exagerado pelo comediante" 22 . A verdade que constrói a partir daí não é mais - ou não tão somente

\footnotetext{
16 Para algum aprofundamento quanto a esse ponto, cf. COSTA, G. Hipocrisia como criação de si. Arte do engano, arte do ator, p. 154-71.

${ }^{17}$ DIDEROT, D. Paradoxo sobre o comediante, p. 163.

${ }^{18}$ Para uma análise acerca do caráter não-duplicável da realidade a partir dos diálogos platônicos: Crátilo e Parmênides, cf. ROSSET, C. O real e seu duplo, p. 59-61.

${ }^{19}$ DIDEROT, D. Paradoxo sobre o comediante, p. 162-5.

${ }^{20}$ Idem, p. 188-9.

${ }^{21}$ PORTICH, A. $A$ arte do ator entre os séculos XVI e XVIII, p. 142.

22 DIDEROT, D. Paradoxo sobre o comediante, p. 167, grifo meu.
} 
- a do acontecimento, do mundo ou do homem, mas a do teatro, que salienta alguns traços e omite outros de menor importância visando à persuasão estética, à ilusão e ao encanto do espectador.

De fato, é nos grandes papéis de teatro que Rosset vê exemplificado o "afastamento de si por si mesmo" quando percebido em outros, naquilo que lhes é ao mesmo tempo indesejável e semelhante. Diz o autor:

\begin{abstract}
Quem aparece no teatro semelhante demais ao eu que se decidiu não ser, será logo, ele próprio, desdobrado segundo a estrutura da duplicação que, acredita-se, já demonstrou sua eficácia no que concerne ao eu. Em lugar da personalidade teatral tal qual ela é, aparece um outro personagem que relega a personalidade incomodamente semelhante para uma espécie de exterioridade mágica, da qual o eu não tem mais nada a temer por estar sem relação com ela. Tartufo, por exemplo, não está aqui, mas em outro lugar; não é nem você nem eu, mas um outro: é isto o que se quer dizer quando declara-se que ele não é sincero, mas sim hipócrita ${ }^{23}$.
\end{abstract}

$\mathrm{Na}$ representação de caracteres incomodamente próximos, portanto, a "personalidade incomodamente semelhante" aparece como que relegada, pelo desdobramento em um "outro", a uma "exterioridade mágica": uma espécie de personagem do personagem, ou ainda, um personagem com vida própria, com o qual o ator já não teria - tal qual os Seis personagens à procura de um ator, de Luigi Pirandello ${ }^{24}$ qualquer relação.

O que se destaca então com o exemplo de Rosset são precisamente os processos de incorporação não-reconhecida de crenças aparentemente contraditórias que configuram o autoengano: o esquecimento ou não-reconhecimento de si como único, em nome de um outro que, irônica ou tragicamente, conduz de volta a si. Mas em que medida esse exemplo se adéqua a tais processos, ou seja, em que medida o ator e a atuação poderiam propriamente elucidá-lo?

A princípio, a resposta seria simples: na medida mesma em que ambos são assim apresentados, isto é, como um ator que não se reconhece em sua própria atuação, e nesse sentido parece não incorporar seu personagem. No entanto, a meu ver, isso deixaria entrever duas dificuldades. A primeira delas estaria em que, ao se tomar esse exemplo, finda-se por limitar a arte do ator meramente àquilo que aparece em palco - ao seu efeito de cena. E com isso restringe-se sua compreensão a uma perspectiva de espectador, atenta apenas ao personagem enquanto obra consumada, obscurecendo - com justa razão - os processos envolvidos em sua constituição. Precisamente por essa compreensão é que se tem a arte do ator como um paradoxo: para atuar, o ator deve deixar de ser. Ao que parece, é essa perspectiva que leva Rosset a ver no "temperamento de ator" uma "ferida narcísica": uma "dúvida quanto a si mesmo, da qual só liberta uma garantia reiterada do outro, no caso, do público" -

23 ROSSET, C. O real e seu duplo, p. 87-88.

24 PIRANDELLO, L. O falecido Mattia Pascal. Seis personagens à procura de um autor. 
estado de dependência em relação ao outro que se aproximaria da mera vaidade. A segunda dificuldade, por sua vez, estaria em que, se aquela aproximação seria facilmente aplicável à teoria do ator e ao paradoxo de Diderot - e de resto, à chamada escola da representação - o mesmo talvez não se pudesse dizer da escola da atuação; particularmente, como veremos a seguir, da teoria do ator de Stanislasvski.

Passemos então a um esboço de resolução para esse paradoxo e, com ele, a um terceiro itinerário no enfrentamento dos acasos.

\section{Paradoxo sobre o comediante: segundo ato}

Se a leitura da arte do ator como um paradoxo é manifesta em uma perspectiva de espectador atenta ao efeito de cena, em uma perspectiva do ator, ao contrário, é precisamente aquilo que se dissimula ao espectador que viria a constituir a sua arte: a atuação enquanto processo de simulação e incorporação do personagem, envolvendo o controle do kairós, da ocasião oportuna à excitação e expressão de determinados afetos e sentimentos.

Um dos aspectos que chamam a atenção em algumas teorias da interpretação desenvolvidas já no século XX, especialmente a de Stanislavski ${ }^{25}$, está precisamente em salientar a importância da sensibilidade para a atuação e a necessidade do desenvolvimento de uma técnica que aproxime, emotivamente, o ator de seu personagem. Diferentemente do que prega a escola da representação, que se poderia aqui remeter à teoria de Diderot, o que Stanislavski propõe com a escola de atuação que, aliás, poderia mesmo ser remetida a Luigi Riccoboni ${ }^{26}$, contemporâneo de Diderot - é precisamente a atenção ao sensivel. Mas não se trata meramente de "copiar

\footnotetext{
25 Para uma contextualização da teoria de Stanilavski e de sua importância como limiar entre o teatro realista e o contemporâneo; e de um modo geral, para uma caracterização deste último em sua amplitude e diversidade de experiências, merece referência, cf. Bornheim, O sentido e a máscara, p. 14-5 e outras. Para Bornheim, do ponto de vista da concepção de teatro, do aspecto cênico, Stanislavski situa-se como um "momento de conclusão", "derradeira etapa de um certo tipo de realismo teatral" - com a decisiva influência de Tchekov. Por outro lado, embora abrangendo uma "extensão dramatúrgica muito grande" e a despeito de ser a teoria até então "mais completa que existe", as técnicas de atuação que desenvolve seriam exequíveis dentro de uma concepção clássica de homem, tendo como pressupostos a ideia de uma "personalidade humana" e uma certa noção de coerência, tanto psicofisiológica como social - inaplicáveis, segundo Bornheim, à dramaturgia de vanguarda. ${ }^{26}$ Com a escola de atuação de Stanislavski e a defesa de uma recorrência ao "material emocional" próprio do ator, vê-se de alguma forma retomada a recomendação de Luigi Riccoboni em Da arte de representar (1728), cujas ideias são indiretamente confrontadas por Diderot: [...] seguir o instinto natural, [...] esquecer os quatro membros e talvez até mesmo o quinto, que é a cabeça; e procurar sentir tão bem aquilo que expões, que acreditem serem teus os interesses de outrem [...]. Sou capaz de apostar [...], não encontrarás em toda a cristandade ninguém que te censure, se medires teus movimentos pelas batidas do coração (RICCOBONI apud PORTICH. $A$ arte do ator entre os séculos XVI e XVIII, p. 155). A defesa de um confronto indireto entre as ideias de Diderot e as de Riccoboni é sustentada por Ana Portich a partir da conotação que a obra de Diderot adquire, de refutação das teses contidas em O Comediante (1747), de Pierre Rémond de Sainte-Albine, "êmulo e colaborador da Comédie Italienne desde os tempos em que Luigi Riccoboni a dirigia" (cf. PORTICH, $A$ arte do ator entre os séculos XVI $e$ XVIII, p. XXXIII). Essa aproximação - e respectivo distanciamento em relação a Diderot - pode ser percebida também em Pensées sur la déclamation, obra citada por Portich, onde Riccoboni sustenta que: "o ofício do comediante será executado a contento se ele comover e iludir a si mesmo e aos demais, tendo o cuidado de não exagerar a ponto de perder os traços humanos" (idem, p. 94).
}

Voluntas: Revista Internacional de Filosofia - periodicos.ufsm.br/voluntas - Santa Maria - Vol. 9, n. 1, jan.-jun. 2018, pp. 161-172 
paixões ou tipos", e sim, de vivê-los - ou melhor, de tê-los vivido e, em cena, rememorar aquilo que os motivou: "Todos esses sentimentos resultam de alguma coisa que se passou primeiro. Nesta coisa, que se passou antes, vocês devem pensar com toda a força" 27 . Não é o caso, portanto, de sentir como o personagem, mas sim, de fazê-lo florescer com seus próprios sentimentos.

É possivel compreender um papel, simpatizar com a pessoa retratada e pôr-se no lugar dela, de modo a agir como essa pessoa agiria. Isso despertará no ator sentimentos que são análogos aos que o papel requer. Mas esses sentimentos pertencerão não à pessoa criada pelo autor da peça, mas ao próprio ator28.

Stanislavski salienta aqui o uso da memória emotiva como forma de fazer os sentimentos brotarem espontaneamente. Diferentemente da "memória das sensações", a das emoções não se basearia diretamente "na experiência ligada aos sentidos", mas só depois de esta ser filtrada pelo tempo que, por si, "não só purifica, mas também transmuda em poesia até mesmo as lembranças dolorosamente realistas" 29 . Isso, claro, dependeria da afinidade do ator com relação ao seu papel; e principalmente, do desenvolvimento de uma técnica capaz de possibilitar, não só que a memória emotiva venha à tona na atuação, mas também que este acervo de sentimentos se amplie. Não se trata, no entanto, de relegar ao inconsciente a tarefa criativa, e sim de conscientemente fazer florescer a inspiração inconsciente:

A nossa arte, portanto, nos ensina [...] a criar conscientemente e certo, pois esse é o melhor caminho para o florescimento do inconsciente, que é a inspiração. Quanto mais momentos conscientemente criadores vocês tiverem nos seus papéis, maiores serão as possibilidades de um fluxo de inspiração $0^{30}$.

Esta técnica consiste basicamente em: "trabalhar a partir da emoção despertada, retrocedendo até o seu estímulo original"31. Para reavivar e ampliar a sua memória de emoções, o ator deve se valer de uma simulação mental - algo próximo das estratégias de deliberação indireta, como o transporte situacional e o mergulho introspectivo, por meio das quais se poderia driblar ou provocar, ainda que de modo não reconhecido, processos involuntários como o choro, por exemplo. O como se, nesse caso, atuaria como uma "alavanca que nos ajuda a sair do mundo dos fatos, erguendonos ao reino da imaginação" 32 .

É preciso ao ator - a meu ver, enfrentando e afirmando a disjunção paradoxal apontada por Rosset - imaginar as circunstâncias dadas, acreditar nessas condições de vida e habituar-se a elas, deixando crescer espontaneamente os sentimentos

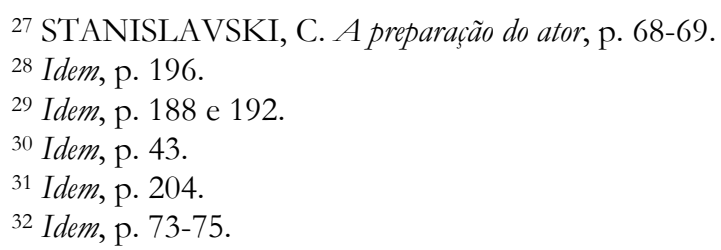


"verdadeiros" e emoções "sinceras", pondo de lado aqueles que são "de origem subconsciente e não estão sujeitos a comandos diretos". Finalmente, quando "as condições interiores estiverem preparadas - e certas - os sentimentos virão à tona espontaneamente"33. Como afirma Stanislavski:

Sempre e eternamente, quando você estiver em cena, você terá de interpretar você mesmo. Mas isto será numa variedade infinita de combinações de objetivos e circunstâncias dadas que você terá preparado para seu papel e que foram fundidas na fornalha da sua memória de emocões. É este o melhor e o único material verdadeiro para a criatividade interior ${ }^{34}$.

Arriscaria que essa necessária atenção para com os próprios sentimentos talvez não esteja assim tão distante daquilo que se apresenta em Paradoxo sobre o comediante como a capacidade de distanciar o sentir do ser sensivel - virtude por meio da qual seria possível escapar ao apego sensível em relação ao personagem. Por outro lado, também para Stanislavski não é esse apego que está em jogo, na medida em que há em sua teoria a preocupação em fomentar no ator a necessária distância artística em relação ao personagem. Apenas, ela não aparece tão às claras como no diálogo de Diderot, na relação de representação entre o ator e seu personagem a partir de um modelo ideal; e sim, na própria atuação, no cultivo de seus próprios sentimentos e vivências.

Expresso na ideia de cultivo, o distanciamento artístico que aqui se apresenta caracterizaria o manuseio do personagem pelo ator, e assim como em Diderot, implicaria a ponderação e o controle acerca do tempo e da ocasião oportunas à excitação de determinados afetos e expressão de um sentimento - o que atualmente se entende por um controle do "timing indutivo", mas que os gregos compreendiam como a atenção ao kairós.

É por esse motivo que a atividade do ator não se confundiria com o autoengano, nem tampouco com o mero embuste ou efeito de cena: os sentimentos que vive e apresenta não são os do personagem, mas os seus próprios, conscientemente cultivados. E não deixa de ser interessante que, nesse momento, a sua arte, a hipocrisia - arte do engano e arte do ator - mostre-se muito mais criativa que imitativa.

Cada uma a seu modo, as teorias de Diderot e principalmente de Stanislavski apontam para a compreensão de que a arte do ator não se resume ao controle dos artifícios utilizados na atuação, ou seja, do efeito de cena visando à ilusão do espectador. Não se trata meramente de uma "arte da administração de impressões" - expressão por si só inartística. Trata-se, sobretudo, remetendo à paraskenê grega, do exercício de certo modo ascético de preparação de si como personagem: no caso de Diderot ${ }^{35}$, pelo

\footnotetext{
33 Idem, p. $78-80$.

${ }^{34}$ Idem, p. 196.

${ }^{35}$ DIDEROT, D. Paradoxo sobre o comediante, p. 186.
} 
treinamento com base em um modelo ideal, até que se chegue ao estado de extenuação, chamado blasés, em que o ator se identifica com seu personagem; já em Stanislavski, pelo cultivo dos próprios sentimentos, com o exercício da imaginação e, porque não, da phantasía.

Longe de cair em autoengano ou de denotar um paradoxo, a arte do ator requereria, antes, o reconhecimento e manuseio de si como ilusão. Aqui, a relutância em se incorporar um personagem, com o consequente desdobramento segundo a estrutura paradoxal da duplicação, apenas atestariam a inadequação ou mesmo o mau preparo do ator para tal papel, cuja atuação, buscando tornar-se o que não se é, não poderia parecer, senão, exagerada e demasiado artificial, além de dependente da aprovação do público. Diria mesmo que só há paradoxo em uma ótica de espectador. Mas se de todo modo insiste-se nessa mirada, a arte do ator seria então a mais adequada a expressar a não menos paradoxal tarefa de criar a si e tornar-se o que se é. Afinal, para dizer com Nietzsche, como tornar-se o que se é, quando não se suspeita sequer remotamente o que é36?

Própria ao ator, nesse sentido, é a capacidade, não apenas de seguir regras de caracterização e constituição de um personagem, mas também de adaptá-las às suas próprias potencialidades e improvisá-las de acordo com a variabilidade das circunstâncias; ou seja, de lidar com a ambiguidade e a contingência, e dominar o instante, a ocasião favorável a determinada combinação de sentimentos. Tais qualidades, necessárias no trato com "realidades fluidas que não cessam nunca de se modificar e que reúnem nelas, a cada momento, aspectos contrários, forças opostas", são aquelas mesmas que, novamente com Détienne e Vernant, caracterizam as formas de inteligência astuciosa e artificiosa entre os gregos. Combinando: sagacidade, sutileza, fingimento, atenção e senso de oportunidade, a mêtis domina "uma situação mutante e em contraste", tornando-se "mais flexível, mais ondulante, mais polimórfica que o escoamento do tempo", mais rápida que o kairós fugaz ${ }^{37}$.

Para além dos dois itinerários que, a meu ver, têm o sujeito como mera presa dos acasos, caberia ainda o terceiro aqui apresentado, que contrapõe à efemeridade a politropia que se assemelha aos acasos para melhor dominá-los - leia-se: incorporálos. Essa arte de exercitar-se para o acaso por meio da mêtis, não para enfrentá-lo, mas para, reconhecendo a sua superioridade, a ele moldar-se - sendo essa a forma de subjugá-lo -, essa arte, própria daquele que é mestre em driblar, improvisar e adaptarse às circunstâncias, enquanto arte do engano e arte do ator, tem um nome: hipocrisia. Naquilo que difere da fuga autoenganada e da aceitação jubilosa - talvez uma mera diferença de perspectiva, mas decisiva na constituição de si como sujeito - esse trabalho de convencimento revela um aspecto da arte do engano e do ator que extrapola os

\footnotetext{
${ }^{36}$ NIETZSCHE, F. Ecce homo, p. 48.

${ }^{37}$ DÉTIENNE, M.; VERNANT, J-P. Métis: as astúcias da inteligência, p. 11 e 27.
} 
limites da avaliação moral radicada na perspectiva do enganado: tão importante quanto o reconhecimento do engano é o manuseio ou manejo de si - envolvendo a antecipação e a autoexperimentação, isto é: a áskêsis. Aspecto que considero decisivo à criação de si e constituição de um êthos.

Encerro reconhecendo que, afinal, o itinerário aqui esboçado, pautado na ficção de se domar o real, finda por retornar, tanto quanto aqueles indicados por Rosset, ao mesmo real do qual se buscou sair. Na melhor das hipóteses, esse inevitável retorno remeteria mais uma vez a Pirandello, que compreende não como trágica, mas como a própria definição de humor, essa luta entre a ilusão "que se insinua em tudo" e a reflexão "que decompõe aquelas ilusões uma a uma", começando pela "interpretação fictícia e sem dúvida sincera de nós mesmos"38. Mas aqui talvez coubesse contrapor, ao primado ontológico do real, a primazia da ética. Irônico ou trágico que seja esse retorno de volta a si, nem por isso, no entanto, o itinerário precisa se dar entre o autoengano e a resignação, cabendo, talvez, uma rota pelas vias da mêtis e da hipocrisia.

Pouco antes de entregar esse texto para publicação, soube com pesar do falecimento de Clément Rosset, filósofo a quem tive, juntamente com o Apoena Grupo de Estudos Schopenhauer-Nietzsche, a oportunidade de dedicar o segundo de nossos encontros anuais (2010) com o estudo de sua obra, particularmente: Schopenhauer, philosophe de l'absurde. Que esse artigo seja, então, a minha modesta homenagem e contribuição ao seu estudo no Brasil.

\section{Referências bibliográficas}

BORNHEIM, G. O sentido e a máscara. São Paulo: Perspectiva, 1975.

COSTA, G. Hipocrisia como criação de si. Arte do engano, arte do ator. Campinas: Phi, 2016.

DETIENNE, M.; VERNANT, J-P. Métis: as astúcias da inteligência. Trad. Filomena Hirata. São Paulo: Odysseus, 2008.

DIDEROT, D. Paradoxo sobre o comediante. Trad. Marilena de Souza Chauí e J. Guinsburg. 2a. Ed. São Paulo: Abril Cultural, 1979 (Coleção Os Pensadores).

KLEIST, H. von. Teatro de marionetes. Trad. Paulo Mendes Campos. Rio de Janeiro: Ministério da Educação e Saúde / Serviço de Documentação, 1952 (Cadernos de Cultura, 9).

NIETZSCHE, F. W. Ecce homo. Trad. Paulo César de Souza. 2a ed. São Paulo: Companhia das Letras, 2004.

PIRANDELLO, L. O falecido Mattia Pascal. Seis personagens à procura de um autor. Trad. M. Silva. São Paulo: Abril Cultural, 1981.

38 PIRANDELLO, L. O falecido Mattia Pascal. Seis personagens à procura de um autor, p. 156. 
PIRANDELLO, L. O humorismo. Trad. D. D. Macedo. São Paulo: Experimento, 1996.

PORTICH, A. A arte do ator entre os séculos XVI e XVIII. Da Commedia dell'arte ao Paradoxo sobre o comediante. São Paulo: Perspectiva, 2008.

ROSSET, C. O real e seu duplo. Ensaio sobre a ilusão. Trad. José Thomaz Brum. Porto Alegre: L\&PM Pocket, 1988.

STANISLAVSKI, C. A preparação do ator. Trad. Pontes de Paula Lima. $4^{\mathrm{a}}$ Ed. Rio de Janeiro: Civilização Brasileira, 1989.

DETIENNE, M. Os mestres da verdade na Grécia arcaica. Trad. Andréa Daher. Rio de Janeiro: Jorge Zahar, 1988.

Recebido: 20/01/18 Received: $01 / 20 / 18$

Aprovado: $11 / 04 / 18$ Approved: 04/11/18 